\title{
PERBEDAAN AKTIVITAS ANTIOKSIDAN DAN TOKSISITAS EKSTRAK ETANOL 96\% DAN EKSTRAK FREEZE DRYING BIJI MANGGA GEDONG (Mangifera indica $\mathrm{L}$ ).
}

\author{
Taty Rusliati Rusli \\ Fakultas Kedokteran Universitas Tarumanagara, Jakarta \\ Email: tatyrusliati@yahoo.co.id
}

\begin{abstract}
ABSTRAK
Mangga Gedong (Mangifera indica) adalah salah satu tanaman yang dapat digunakan untuk pengobatan alternatif sebagai aktivitas antioksidan. Tujuan penelitian adalah menguji perbedaan aktivitas antioksidan dan toksisitas ekstrak Etanol 96\% biji mangga yang dikeringkan dengan rotavapor dan ekstrak yang dikeringkan dengan freeze drying. Metode yang dilakukan dalam penelitian ini untuk aktivitas antioksidan adalah peredaman radikal bebas 1,1-Diphenyl-2-Pikril-Hidrazil (DPPH), sedangkan untuk uji toksisitas adalah dengan Brine Shrim Lethally Test (BSLT). Hasil uji antioksidan didapatkan nilai $\mathrm{IC}_{50}$ untuk ekstrak Etanol 96\%, ekstrak freeze drying, pembanding Asam askorbat dan BHT, berturut adalah : 23,18 ppm ; 34,36 ppm ; 5,08 ppm dan 8,31 ppm. Hasil ini menunjukkan bahwa ekstrak kering hasil freeze drying memiliki aktivitas lebih tinggi dibandingkan dengan ektrak Etanol 96\%. Namun jika dibandingkan dengan Asam askorbat dan BHT, aktivitas kedua ekstrak ini masih lebih rendah. Selanjutnya hasil uji toksisitas BSLT semua ekstrak, baik ekstrak Etanol 96\% kental maupun ekstrak kering freeze drying menunjukkan sifat tidak toksik.
\end{abstract}

Kata Kunci: Mangga Gedong, Antioksidan, DPPH, BSLT, Freeze drying

\begin{abstract}
Gedong mango (Mangifera indica, L) is one of the plants that can be used for alternative medicine as an antioxidant activity. The research objective was to test differences in antioxidant activity and toxicity of $96 \%$ ethanol extract of dried mango seed extract with a rotary evaporator and dried by freeze drying. The method used in this research for its antioxidant activity is the reduction method of free radical 1,1-Diphenyl-2-Pikril-Hidrazil (DPPH), while for the toxicity test is Brine Shrim Lethally Test (BSLT). Antioxidant test results obtained $\mathrm{IC}_{50}$ value for $96 \%$ Ethanol extract, extract of freeze drying, the comparison ascorbic acid and BHT, are respectively: $23.18 \mathrm{ppm} ; 34.36 \mathrm{ppm} ; 5.08 \mathrm{ppm}$ and $8.31 \mathrm{ppm}$. These results indicate that the dry extract of freeze drying results had higher activity compared with $96 \%$ ethanol extracts. However, when compared with ascorbic acid and BHT, the activity of the extracts is still lower. The results of toxicity tests BSLT all extracts, both $96 \%$ Ethanol extract thick or dry extracts freeze drying results showed no toxic properties.
\end{abstract}

Keywords: Gedong Mango, Antioxidant, DPPH, BSLT, Freeze drying 


\section{PENDAHULUAN}

Indonesia merupakan Negara yang kaya akan sumber daya alam. Begitu banyak komponen sumber daya alam yang dapat dimanfaatkan oleh manusia, baik untuk sandang, pangan dan papan serta kebutuhan hidup lainnya. Salah satu sumber daya alam yang sangat penting adalah tumbuh-tumbuhan.

Mangga adalah salah satu dari sekian banyak jenis tanaman yang tumbuh di Indonesia. Tanaman mangga ini pada mulanya berasal dari India, oleh karena itu bernama latin Mangifera indica. Di pasar, varietas mangga beraneka macam, ada mangga arum manis, gedong, mana lagi dan lain-lain. Tercatat, ada 2000 jenis varietas. mangga memiliki khasiat yang luar biasa, seperti contohnya dapat menyembuhkan penyakit influenza, penambah napsu makan, menyembuhkan luka pada kulit, radang tenggorokan atau batuk, dan masih banyak penyakit lainnya. Buah mangga memiliki kandungan vitamin $\mathrm{A}, \mathrm{C}$ dan E yang sangat bagus untuk keremajaan kulit dan mencegah kanker karena mangga merupakan sumber beta-karoten yang disebut crytoxanthin, kalium, dan vitamin C. Betakaroten adalah zat yang di dalam tubuh akan diubah menjadi vitamin A, yaitu zat gizi yang penting untuk fungsi retina. Sedangkan Beta-karoten dan vitamin C merupakan zat bersifat antioksidan, senyawa yang dapat memberikan perlindungan terhadap kanker karena dapat menetralkan radikal bebas. Antioksidan sintetik seperti Butilat hidroksi toluen (BHT) telah banyak digunakan dalam industri, tetapi antioksidan ini diduga mengakibatkan kerusakan hati dan bersifat karsinogenik. Di sisi lain sumber alami dari tanaman seperti vitamin $\mathrm{C}$, vitamin $\mathrm{E}$, karoten serta senyawa-senyawa metabolit sekunder golongan tanin dan fenolik telah diketahui memiliki aktivitas antioksidan ${ }^{1,2}$. Walaupun biji mangga dapat digunakan sebagai makanan, namun penelitian atau kajian ilmiah tentang biji mangga belum banyak dilakukan sehingga pemanfaatannya juga belum dapat dimaksimalkan ${ }^{3,4}$. Ekstrak kering dibuat dengan menggunakan metode pengeringan beku (freeze drying). Metode ini dapat digunakan untuk menangani bahan-bahan cair seperti pada larutan, cairan kental dan pasta tipis. Bahan yang bersifat sensitif terhadap temperatur tinggi dapat dikeringkan dengan metode pengeringan beku ${ }^{5}$. Penelitian ini dilakukan uji aktivitas antioksidan dengan metode peredaman radikal bebas (1,1-difenil-2-pikrilhidrazil) DPPH dan uji toksisitas dengan metode BSLT. Metode peredaman radikal bebas DPPH merupakan pengujian yang mudah dan cepat untuk menguji aktivitas antioksidan pada suatu sampel ${ }^{6-10}$ dan uji toksisitasnyanya dilakukan dengan metode BSLT (Brine Shrimp Lethality Test), metode ini digunakan untuk skrining awal terhadap zat aktif yang terkandung dalam ekstrak tanaman karena murah, cepat dan dapat dipercaya ${ }^{11}$.

\section{METODOLOGI PENELITIAN}

\section{Bahan}

Biji mangga gedong matang, Etanol 96\%, amonia 30\%, metanol pro analisis, etanol pro analisis, larva udang Artemia salina Leach, garam laut, aquadest, DPPH (1,1-difenil-2pikrilhidrazil), vitamin C, BHT.

\section{Peralatan}

Freeze dryer, Spektrofotometer uv-visible (Shimadzu 1700), vakum rotary evaporator (Buchi RII), orbital shaker, timbangan mikro (Mettler MT5), oven (Memmert), alat-alat gelas, timbangan analitik (Kern ABT 120-5DM), Karl Fisher (Metrohm $870 \mathrm{KF}$ Trinitro plus), aluminium foil, lumpang dan alu, penangas air, kertas saring, mikropipet $5 \mu \mathrm{L}-1000 \mu \mathrm{L}$, lampu TL 18 watt, kotak penetasan 


\section{Prosedur}

Serbuk biji mangga gedong diekstraksi dengan cara maserasi pada suhu kamar menggunakan pelarut etanol 96\%, dipekatkan menggunakan rotavapor, kemudian dikeringkan menggunakan pengering beku (freeze drying) kemudian dilakukan uji aktivitas antioksidan dengan metode DPPH dan toksisitas dengan metode BSLT.

\section{Pengumpulan dan Pengolahan Sampel}

Sampel yang digunakan adalah biji mangga gedong matang yang di ambil dari beberapa tempat dan dicampur menjadi satu sampel. Biji mangga segar dibersihkan, diambil kernelnya kemudian dikeringkan dan digiling menjadi serbuk hingga didapat $1 \mathrm{~kg}$ serbuk biji mangga kering.

\section{Penyiapan ektrak.}

Sebanyak $250 \mathrm{~g}$ biji mangga gedong matang yang sudah dibuat serbuk dimaserasi menggunakan Etanol 96\% dalam bejana tertutup sampai tersari sempurna, selanjutnya disaring. Filtrat diuapkan menggunakan Rotavapor pada suhu $40^{\circ} \mathrm{C}$ hingga diperoleh Ekstrak kental.

\section{Pengeringan ekstrak dengan menggunakan metode freeze drying}

Sebanyak $10 \mathrm{~g}$ Ekstrak kental biji mangga gedong matang dilakukan pengeringan dengan menggunakan metode freeze drying. Produk hasil freeze drying dilakukan penetapan kadar air dengan metode Karl Fisher ${ }^{12}$. Hasil produk kemudian dilakukan uji aktivitas antioksidan dengan metode DPPH dan toksisitas dengan metode BSLT.

\section{Uji aktivitas antioksidan dengan peredaman radikal bebas DPPH.}

Larutan induk sampel 1000 ppm dibuat dengan menimbang 19,8 gram sampel yang dilarutkan dengan $25 \mathrm{~mL}$ metanol. Kemudian untuk membuat larutan sampel dengan konsentrasi 20, 40, 80, dan $100 \mathrm{ppm}$, sebanyak 0,2 mL, 0,4 mL, 0,8 mL, dan $1 \mathrm{~mL}$ larutan induk dimasukkan ke dalam lima labu teukur $10 \mathrm{~mL}$. Larutan vitamin C dan BHT sebagai pembanding dibuat dengan konsentrasi 20, 40, 80, dan 100 ppm. Ke dalam masing-masing tabung ditambahkan 0,1 mM larutan DPPH dan diencerkan dengan metanol sampai 5,0 $\mathrm{mL}$. Selanjutnya diinkubasi dalam penangas air $37^{\circ} \mathrm{C}$ selama 30 menit. Serapan diukur dengan spektrofotometer pada panjang gelombang maksimun yaitu $\lambda 517 \mathrm{~nm}$. Nilai $\mathrm{IC}_{50}$ (Inhibition Concentration 50) adalah konsentrasi antioksidan $(\mu \mathrm{g} / \mathrm{mL})$ yang mampu memberikan persen peredaman radikal sebanyak 50\% dibanding kontrol melalui suatu persamaan garis. Nilai $\mathrm{IC}_{50}$ diperoleh dari perpotongan garis antara $50 \%$ daya hambatan dengan sumbu konsentrasi, kemudian masukkan kepersamaan $\mathrm{y}=\mathrm{a}+\mathrm{bx}$ dimana $\mathrm{y}=50$ dan nilai x menunjukkan $\mathrm{IC}_{50}$. Menurut Blois (1958) dalam Hanani, (2005), suatu bahan dapat dikatakan sebagai antioksidan yang kuat jika memiliki nilai $\mathrm{IC}_{50}<200 \mu \mathrm{g} / \mathrm{mL}^{13}$.

\section{Uji toksisitas dengan metode BSLT}

Terhadap Ekstrak kental dan Ekstrak kering freeze drying biji mangga gedong matang dilakukan uji toksisitas menggunakan metode BSLT (Meyer et al.) ${ }^{\text {(11) }}$ dengan menggunakan larva Artemia salina Leach. Mula-mula telur Artemia salina ditetaskan didalam air laut buatan (38 g garam tanpa iodium dalam $1000 \mathrm{~mL}$ air biasa) di bawah lampu TL 18 watt. Media penetasan telur diberi aerasi udara. Setelah 48 jam larva menetas menjadi nauplii dan siap untuk digunakan. Nauplii dimasukkan ke dalam 4 vial yang berisi larutan sampel dengan konsentrasi 62,5, 125, 250 dan 500 ppm dengan 3 kali ulangan. Semua vial di inkubasi pada suhu kamar selama 24 jam di bawah penerangan lampu TL 18 watt. Pengamatan dilakukan setelah 24 jam dengan melihat jumlah Artemia salina yang mati pada setiap konsentrasi. Penentuan harga $\mathrm{LC}_{50}$ dilakukan menggunakan 
analisis probit. Menurut Meyer, suatu ekstrak dikatakan toksik terhadap Artemia salina Leach apabila nilai $\mathrm{LC}_{50}<1000 \mathrm{ppm}$,

\section{HASIL DAN PEMBAHASAN}

\section{Ekstraksi}

Ekstraksi serbuk biji mangga dengan Etanol $96 \%$ bertujuan untuk membuka jaringan-jaringan dalam serbuk, sehingga senyawa-senyawa metabolit sekunder yang terkandung dalam serbuk biji mangga dapat terekstraksi ke dalam pelarut.

Maserasi dilakukan sebanyak 3 kali dengan menggunakan 3L Etanol sebagai pelarut. Maserasi dilakukan dengan pengadukan beberapa kali supaya merata dan dilakukan penyaringan setiap tiga hari sekali. Untuk mengetahui kandungan senyawa fenolik yang terdapat dalam ekstrak dilakukan uji dengan $\mathrm{FeCl}_{3}$, dalam hal ini pada maserasi yang ke 3 dinyatakan ekstraksi sudah selesai dan dilanjutkan ke tahap berikutnya.

Ekstrak hasil maserasi dievaporasi dengan menggunakan alat rotary evaporator, agar ekstrak hasil maserasi kering dan pelarut Etanol menguap serta terpisah dari sampel dalam wadah terpisah.

Senyawa metabolit sekunder yang polar biasanya termasuk dalam jenis fenolik, flavonoid, dan alkaloid. Tetapi pada maserasi dengan etanol ini senyawa metabolit sekunder yang semi polar (terpenoid) dan non polar (steroid) juga dapat terekstraksi. Sehingga demikian ekstraksi dengan etanol saja sudah cukup untuk mengekstraksi senyawa metabolit sekunder yang ada dalam biji mangga gedong

Hasil evaporasi sampel diperoleh Ekstrak kental berbentuk pasta coklat yang lengket dan berbau wangi mangga sebanyak 32,8 $\mathrm{g}$.

\section{Pengeringan ekstrak dengan menggunakan metode freeze}

Hasil dari proses pengeringan dengan metode freeze drying, diperoleh kadar air sebesar $8,08 \%$. Syarat kadar air yang diperbolehkan untuk dapat diproses selanjutnya adalah kurang dari $10 \%$. Organoleptis dari serbuk tersebut sangat higroskopis, yang pada saat kontak dengan udara secara cepat berubah bentuk dari serbuk menjadi cairan kental seperti semula, sehingga penyimpanannya dilakukan dalam desikator.

\section{UJI ANTIOKSIDAN}

Hasil Uji aktivitas antioksidan Ekstrak kental, Ekstrak kering freeze drying, pembanding Asam askorbat dan BHT, maka didapat hasil seperti dalam Tabel 1. berikut.

Tabel 1. Perbandingan nilai $\mathrm{IC}_{50}$ Ekstrak kental, Ekstrak kering freeze drying, pembanding Asam Askorbat, dan BHT

\begin{tabular}{|c|c|c|c|c|c|c|c|c|c|}
\hline \multirow{2}{*}{$\begin{array}{c}\mathrm{N} \\
\mathrm{o}\end{array}$} & \multicolumn{3}{|c|}{ Sampel } & \multicolumn{2}{c|}{ Sampel } & \multicolumn{2}{c|}{ Pembanding } & \multicolumn{2}{c|}{ Pembanding } \\
\cline { 2 - 10 } & $\begin{array}{c}\mathrm{C} \\
(\mathrm{ppm})\end{array}$ & Serapan & $\begin{array}{c}\mathrm{IC}_{50} \\
(\mathrm{ppm})\end{array}$ & Serapan & $\begin{array}{c}\mathrm{IC}_{50} \\
(\mathrm{ppm})\end{array}$ & Serapan & $\begin{array}{c}\mathrm{IC}_{50} \\
(\mathrm{ppm})\end{array}$ & Serapan & $\begin{array}{c}\mathrm{IC}_{50} \\
(\mathrm{ppm})\end{array}$ \\
\hline 1 & 20 & 0.403 & & 0.362 & & 0.201 & & 0.245 & \\
2 & 40 & 0.339 & $\mathbf{3 4 . 3 5}$ & 0.234 & $\mathbf{2 3 . 1 8 5}$ & 0.102 & $\mathbf{5 , 0 8}$ & 0.123 & $\mathbf{8 , 3 1}$ \\
3 & 80 & 0.158 & & 0.092 & & 0.042 & & 0.059 & 0.032 \\
4 & 100 & 0.128 & 0.081 & 0.018 & & 0.032 \\
\hline
\end{tabular}


Dari Tabel 1 terlihat hasil pengujian aktivitas antioksidan terhadap sampel Ekstrak kental dan Ekstrak kering freeze drying menunjukan sifat antioksidan yang cukup tinggi. Hal ini ditunjukan oleh nilai IC $_{50}$ untuk ke dua jenis ekstrak yang relatif kecil. Dari kedua ekstrak ini, diperoleh bahwa Ekstrak kering freeze drying memiliki aktivitas lebih tinggi dari Ekstrak kental dengan nilai IC $_{50}$ berturut sebesar 23,18 ppm dan 34,36 ppm. Jika dibandingkan dengan antioksidan Asam askorbat dan BHT, yang nilai IC $_{50}$ nya masing masing sebesar 5,08 ppm dan 8,31 ppm, maka aktivitas antioksidan kedua ekstrak ini masih dibawah Asam askorbat dan BHT.

Dengan demikian dapat dinyatakan bahwa, ekstrak hasil pengeringan dengan metode freeze drying mempunyai aktivitas lebih tinggi dibandingkan ekstrak yang hanya dikeringkan dengan evaporator saja. Hal ini mungkin dikarenakan pada ekstrak hasil freeze drying mengandung kadar air yang lebih sedikit bila dibandingkan dengan ekstrak hasil pengeringan evaporator.

\section{Uji Toksisitas Dengan Metode BSLT (Brine Shrimp Lethality Test)}

Hasil pengujian toksisitas dengan metode BSLT terhadap Ekstrak kental dan Ekstrak kering freeze drying didapatkan nilai $\mathrm{LC}_{50}$ seperti pada Tabel 4 berikut :

Tabel 2. Nilai $\mathrm{LC}_{50}$ dari hasil uji toksisitas Ekstrak kental, Ekstrak kering freeze drying

\begin{tabular}{|c|c|c|}
\hline & \multicolumn{2}{|c|}{$\mathrm{LC}_{50}(\mathrm{ppm})$} \\
\hline $\begin{array}{c}\text { Konsentrasi } \\
\text { sampel }\end{array}$ & Ekstrak kental & $\begin{array}{c}\text { Ekstrak kering } \\
\text { freeze drying }\end{array}$ \\
\hline $96 \%$ & 494.616 & 467.609 \\
\hline
\end{tabular}

Nilai LC $_{50}$ dari hasil uji toksisitas Ekstrak kental dan Ekstrak kering hasil freeze drying disajikan pada Gambar 1.

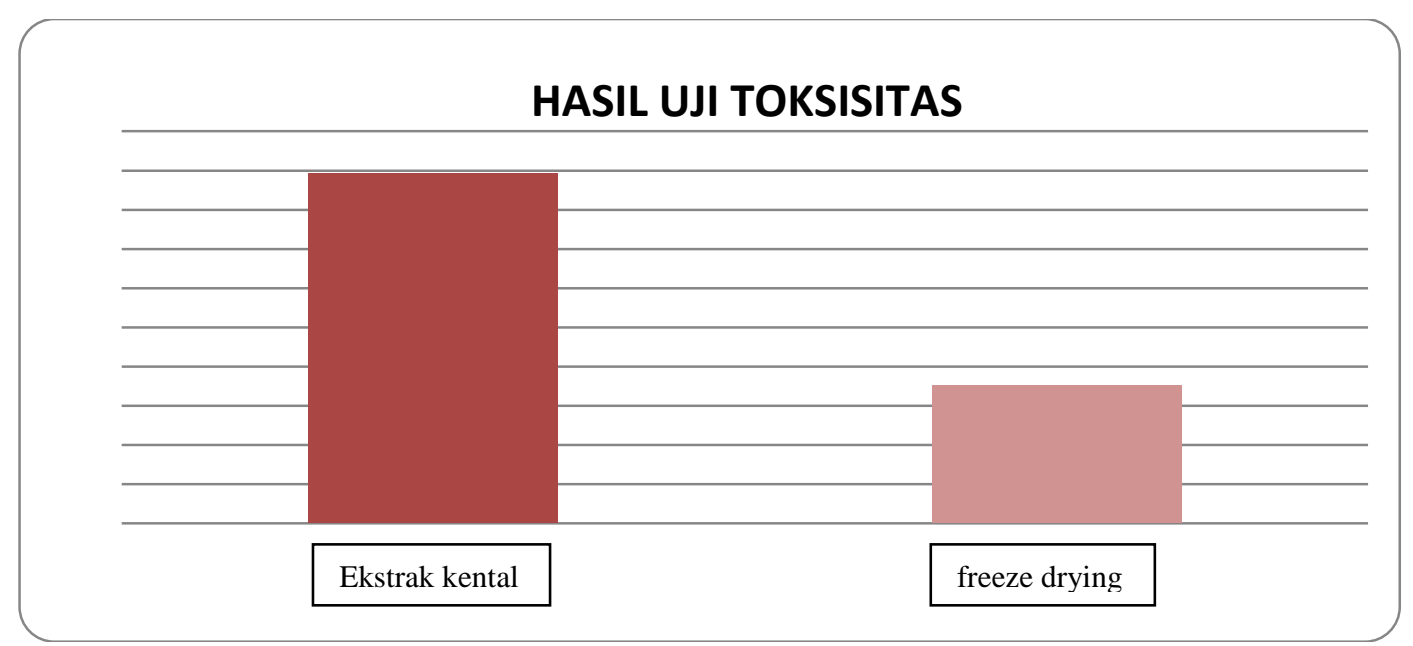

Gambar 1. Nilai LC 50 Hasil uji toksisitas Ekstrak kental dan Ekstrak kering hasil freeze drying

Dari hasil uji toksisitas pada Gambar 1, terlihat bahwa Ekstrak kental memiliki toksisitas lebih tinggi dibandingkan dengan Ekstrak kering hasil freeze drying. Pada pengamatan percobaan memang terdapat perubahan daya toksisitas ditiap perlakuan yang diterapkan terhadap ekstrak, namun pada Ekstrak kering freeze drying terlihat lebih 
tidak stabil. Hal ini mungkin disebabkan oleh proses pendinginan pada saat pengeringan yang dapat mengakibatkan terjadinya penurunan daya toksisitas ekstrak, atau dengan kata lain bahwa ekstrak memiliki kestabilan yang rendah terhadap pendinginan. Apabila dikonversikan terhadap tingkatan toksisitas berdasarkan nilai $\mathrm{LC}_{50}$ yang diperoleh, maka baik Ekstrak kental maupun Ekstrak kering hasil freeze drying dapat digolongan bersifat nontosik.

\section{KESIMPULAN}

- $\quad$ Ekstrak kering biji mangga gedong hasil freeze drying menunjukkan daya antioksidan yang sangat kuat dengan nilai $\mathrm{IC}_{50}$ sebesar $23.18 \mathrm{ppm}$, yang mendekati nilai $\mathrm{IC}_{50}$ Asam askorbat dan BHT, sedangkan Ekstrak kental mempunyai aktivitas antioksidan sedikit lebih lemah

- $\quad$ Uji toksisitas BSLT terhadap Ekstrak kental dan Ekstrak kering freeze drying menunjukkan tidak bersifat toksik.

- $\quad$ Semua ekstrak Etanol biji mangga gedong yang diuji dapat dinyatakan memiliki potensi sebagai bahan obat antioksidan yang aman dari bahan alami.

\section{SARAN}

- $\quad$ Agar dilakukan penelitian lanjutan dengan mengisolasi senyawa antioksidan yang terkandung dalam biji mangga gedong.

\section{ACKNOWLEDGE}

Peneliti mengucapkan terimakasih kepada Lembaga Penelitian dan Publikasi Ilmiah Universitas Tarumanagara yang telah memberi dana untuk penelitian ini

\section{DAFTAR PUSTAKA}

1. Jayaprakasha, G. K., Selvi, T., Sakariah., 2003,K. K., Antibacterial and Antioxidant Activities of Grape (Vitis vinisvera) seed extracts., Food Research International, 36, hal. $117-122$

2. Afriansyah. Nuri. 2007. Khasiat buah mangga untuk kesehatan. http://www.smallcrab.com/kesehatan/295-khasiat-buah-mangga-untuk-pengobatan. Diunduh tanggal 29/5/10 jam 13.30

3. Winarno, F.G., 1989. Kimia Pangan dan Gizi, PT Gramedia, Jakarta.

4. Anonim, 2009.Standar Operasional Pengolahan Buah Mangga. Direktorat Jendral Pengolahan Hasil Pertanian Departemen Pertanian.

5. Jain MS, Lohare GB, Bari MM, Chavan RB, Barhate SD, Shah CB., 2011.Spray drying in pharmaceutical industry: a review. Reseacrh J. Pharma. Dosage and Tech.; 4(2):74-79.

6. Jayaprakasha, G. K., Selvi, T., Sakariah, K. K., Antioxidant Activy of Grape seed (Vitis vinisvera) extracts.on peroxidaion models in vitro, Food Chemisry, Jain MS, Lohare GB, Bari MM, Chavan RB, Barhate SD, Shah CB., 2011.Spray drying in pharmaceutical industry: a review. Reseacrh J. Pharma. Dosage and Tech.; 4(2):74-79.

7. Edhisambada., Metode Uji Aktivitas Antioksidan Radikal 1,1-difenil-2pikrilhidrazil (DPPH), http://www.google, 27 Juli 2011, pukul 10.40.

8. Thitilertdecha, N., Teerawutgulrag, A., Rakariyatham, N,.Antioxidant and Antibacterial Rieger M. Martin, ph.D. Harry's Cosmeticology. Eight edition.New york. Hal 471-83.

9. Chanwitheesuk, A., Teerawutgulrag, A., Rakariyatham, N.,2009. Screening of Antioxidant Activity and Antioxidant Coumpounds some Edible Plants of Thailand, Food Chemistry, 92, hal. 491-497 .

10. Molyneux P.,2004. The use of stable free radical diphenylpicrylhydrazyl (DPPH) for estimatif antioxidant activity. Songklanakarin J. Sci. Technol.. 26 (2) : 211-219. 
11. Meyer BN, Ferrigni BN, Putnam JE, Jacobsen LB, Nichols DF, McLaughlin JL.,1982. Brine shrimp a convenient general bioassay for active plant constituens. Planta Med.;45(5):31-34.

12. Shukla S., 2011. Freeze drying process: a review. Int.J.Pham.Sci. and Reseacrh.; 2(12).h. 3061-3068.

13. Hanani E, Abdul M, Ryany S., 2005. Identifikasi senyawa antioksidan dalam Spons Callyspongia sp dari Kepulauan Seribu. Majalah Ilmu Kefarmasian. ; (2):127 - 133. 